\title{
The Great Gut Mimicker: A case report of MIS-C and appendicitis clinical presentation overlap in a teenage patient
}

\author{
Michelle Hwang, Kelsey Wilson, Lisa Wendt, Joshua Pohlman, Emily Densmore, Caitlin Kaeppler, \\ Kyle Van Arendonk and Sarah Yale
}

\begin{abstract}
Background: Abdominal pain and other gastrointestinal symptoms are common presenting features of multisystem inflammatory syndrome in children (MIS-C) and can overlap with infectious or inflammatory abdominal conditions, making accurate diagnosis challenging.

Case Presentation: We describe the case of a 16-year-old female who presented with clinical symptoms suggestive of appendicitis and an abdominal computed tomography (CT) that revealed features concerning for appendicitis. After laparoscopic appendectomy, histopathology of the appendix demonstrated only mild serosal inflammation and was not consistent with acute appendicitis. Her overall clinical presentation was felt to be consistent with MIS-C and she subsequently improved with immunomodulatory and steroid treatment.

Conclusions: We note that MIS-C can mimic acute appendicitis. This case highlights MIS-C as a cause of abdominal imaging with features concerning for appendicitis, and MIS-C should be considered in the differential for a patient with appendicitis-like symptoms and a positive COVID-19 IgG. Lab criteria, specifically low-normal white blood cell count and thrombocytopenia, appears to be of high relevance in differing MIS-C from acute appendicitis, even when appendix radiologically is dilated.
\end{abstract}

Keywords: Appendicitis, appendectomy, MIS-C, COVID-19, radiologic appendicitis mimic

\section{Background}

Studies of coronavirus disease 2019 (COVID-19) in children have demonstrated an overall milder clinical course and more favorable outcomes compared to adults. [1-3] However, there is a subset of pediatric patients who develop multisystem inflammatory syndrome in children (MIS-C), a hyperinflammatory state that is temporally related to a recent infection with severe acute respiratory syndrome coronavirus 2 (SARS-CoV-2). [3] These patients may exhibit features of Kawasaki disease, signs of systemic inflammation, end organ dysfunction and

\footnotetext{
* Correspondence: syale@mcw.edu

Department of Pediatrics, Medical College of Wisconsin, Children's Corporate Center Suite 560, 999 North 92nd Street, Wisconsin 53226 Milwaukee, USA
}

shock. Laboratory features include elevated inflammatory markers, lymphopenia, neutrophilia, and thrombocytopenia. [4-6] The presence of high fever, rash, conjunctivitis, severe abdominal pain, and neck pain, with a history of SARS-CoV-2 exposure are "red flags" for MIS-C. [5].

Up to $84 \%$ of patients with MIS-C have gastrointestinal symptoms (abdominal pain, nausea, vomiting, diarrhea) as a prominent presenting characteristic. [6, 7] Several reports describe patients with MIS-C whose presentation is concerning for a surgical diagnosis, prompting abdominal imaging and/or operative intervention. [6-9] In this case report, we describe an adolescent whose presentation with MIS-C included clinical

(C) The Author(s). 2021 Open Access This article is licensed under a Creative Commons Attribution 4.0 International License, which permits use, sharing, adaptation, distribution and reproduction in any medium or format, as long as you give appropriate credit to the original author(s) and the source, provide a link to the Creative Commons licence, and indicate if changes were made. The images or other third party material in this article are included in the article's Creative Commons licence, unless indicated otherwise in a credit line to the material. If material is not included in the article's Creative Commons licence and your intended use is not permitted by statutory regulation or exceeds the permitted use, you will need to obtain permission directly from the copyright holder. To view a copy of this licence, visit http://creativecommons.org/licenses/by/4.0/ The Creative Commons Public Domain Dedication waiver (http://creativecommons.org/publicdomain/zero/1.0/) applies to the data made available in this article, unless otherwise stated in a credit line to the data. 
and radiologic signs of appendicitis but had a negative appendectomy.

\section{Case Presentation}

A previously healthy 16-year-old female presented with a four-day history of abdominal pain, vomiting, fever, headache, myalgias and cough. Her initial vital signs in the referring emergency department were temperature $39.4^{\circ}$ Celsius, pulse 154 , respiratory rate 16 , blood pressure 115/61, and oxygen saturation $96 \%$. Physical examination was notable for pallor and right lower quadrant (RLQ) abdominal tenderness without guarding or rebound. Initial laboratory testing significant for white blood cell (WBC) count $5.810^{\wedge} 3 / \mathrm{uL}$ (reference range 410.5) with $93 \%$ neutrophils, hemoglobin 11.9 g/dL (1215), platelets $10210^{\wedge} 3 / \mathrm{uL}(150-450)$, C-reactive protein $11 \mathrm{mg} / \mathrm{dL}(0-1.0)$, erythrocyte sedimentation rate 26 $\mathrm{mm} / \mathrm{hr}(0-20)$, and procalcitonin $0.50 \mathrm{ng} / \mathrm{mL}(<0.09)$. Urine hCG negative. Urinalysis showed trace leukocyte esterase (negative), negative nitrites, and 1-5 WBCs (0). Contrast-enhanced computed tomography (CT) of the abdomen/pelvis showed mesenteric edema, dilation of the appendix $(8 \mathrm{~mm})$, and fat stranding throughout the lower abdomen and pelvis. She received two intravenous (IV) fluid boluses, anti-pyrectics and was transferred to our pediatric hospital.

On arrival she was evaluated by the pediatric surgery team who felt her presentation was not consistent with acute appendicitis. Further history and exam revealed that she had mild bilateral conjunctival injection and neck tenderness in addition to RLQ pain and had a positive SARS-CoV-2 polymerase chain reaction (PCR) test one month prior (she was asymptomatic but underwent testing due to several family members testing positive).

Additional labs were obtained with concern for MIS-C and were significant for a positive SARS-CoV-2 IgG antibody test and normal troponin and N-terminal ProBrain Natriuretic Peptide. Given fever, positive SARSCoV-2 IgG, laboratory evidence of inflammation, and multisystem involvement she was hospitalized for further monitoring and treatment of MIS-C.

Overnight, the patient was persistently febrile and tachycardic. She also reported increasing RLQ pain and exhibited new abdominal rebound tenderness. The attending pediatric radiologist's review of the prior CT concluded that the imaging was consistent with acute appendicitis as there was dilation of the appendix, measuring $8 \mathrm{~mm}$, mild appendiceal mucosal hyperenhancement and adjacent mesenteric fat stranding (Fig. 1). The patient's care was re-discussed with pediatric surgery and together the multidisciplinary team was unable to definitively rule out appendicitis as a concurrent pathology. While a diagnosis of MIS-C generally requires exclusion of other etiologies, it was felt that she could have appendicitis and MIS-C simultaneously. Empiric treatment for appendicitis was started with piperacillintazobactam. The surgical team reviewed the risks and benefits of non-operative management with continued antibiotics versus diagnostic laparoscopy and appendectomy. Surgical management was selected. Echocardiogram was obtained to assess for cardiac involvement and showed normal cardiac function and no dilation of the coronary arteries. She remained stable on the acute floor on hospital day two and therapy with intravenous

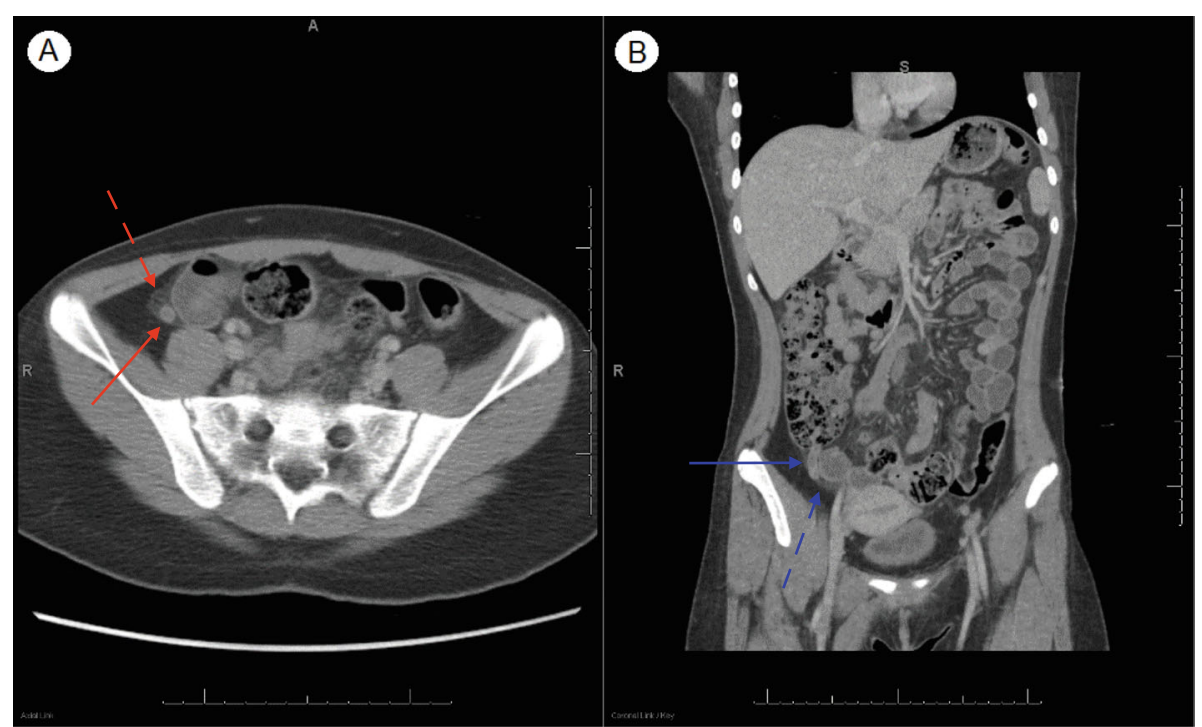

Fig. 1 CT abdomen/pelvis. (A) Appendix (red solid arrow) wall thickness $>3 \mathrm{~mm}$. Lack of luminal air, appendix fluid depth > 2.6mm, and hyperdensity. Red dashed arrow shows peri-appendiceal fat stranding. (B) A diameter of $8 \mathrm{~mm}$ (blue solid arrow) with inflammatory fat stranding (blue dashed arrow), most pronounced around the cecum 
immune globulin (IVIG) and aspirin were ordered for treatment of MIS-C. However, given the timing of when surgery could take her to the operating room, she underwent diagnostic laparoscopy and appendectomy first. She was found to have a grossly normal appendix with no inflammation to suggest appendicitis (Fig. 2). As a surgeon's intra-operative "eyeball" assessment of appendicitis is not perfect and the risk of appendectomy while undergoing laparoscopy is low the decision was made to complete appendectomy. Histologic findings revealed only mild chronic serosal inflammation and edematous mesothelium; it did not show the transmural acute inflammation diagnostic of appendicitis. Piperacillintazobactam was discontinued and the patient was returned to the acute care floor for post-surgical monitoring and MIS-C treatment with IVIG infusion $(2 \mathrm{~g} / \mathrm{kg})$ and aspirin $(81 \mathrm{mg})$.

On hospital day three she completed IVIG therapy, and her blood pressure and fever curve improved. Repeat labs showed worsening lymphocytopenia, anemia, and thrombocytopenia and hypoalbuminemia. She then developed tachycardia and hypotension refractory to fluid resuscitation and given concern for refractory MIS$\mathrm{C}$, she was started on corticosteroid therapy $(2 \mathrm{mg} / \mathrm{kg}$ twice daily). She was transferred to the intensive care unit and started on norepinephrine $(0.02 \mathrm{mcg} / \mathrm{kg} / \mathrm{min})$ for hemodynamic support, which she required for 24 hours. The patient stabilized and was then transferred back to the acute care floor with improvement of her pancytopenia over the next two days. She was discharged home in stable condition on day seven of hospitalization to complete a course of low dose aspirin and a steroid taper.

At her follow-up cardiology appointment four weeks after discharge, she was asymptomatic, but echocardiogram showed moderately dilated right and left coronary arteries with normal ventricular function. She remained

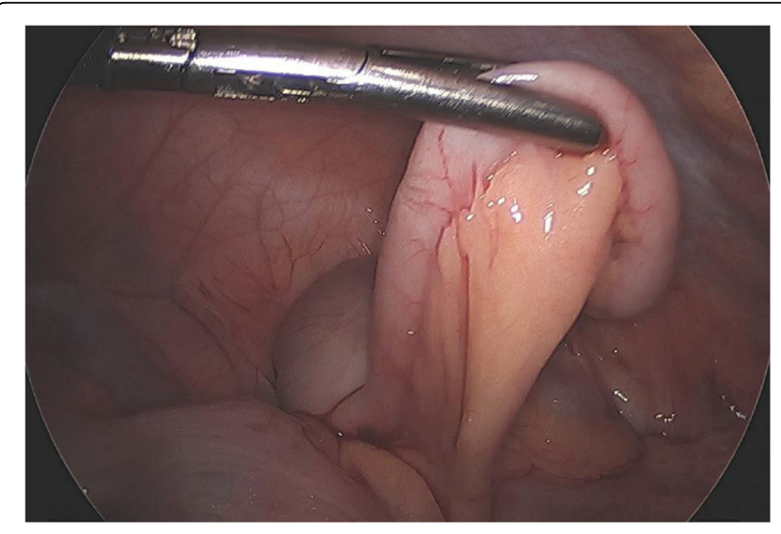

Fig. 2 Intraoperative photograph revealing a grossly normal appendix without signs of inflammation on daily aspirin with close cardiology follow up to monitor progression of her coronary involvement.

\section{Discussion and Conclusions}

There is increasing recognition of gastrointestinal involvement in patients with COVID-19 and MIS-C. Several case reports describe patients who present with typical symptoms of appendicitis who are also found to be infected with SARS-CoV-2 virus or meet the diagnosis for MIS-C. [10-12] Studies have demonstrated that most children with MIS-C will present with gastrointestinal (GI) symptoms. [4, 7] MIS-C should be high on the differential for patients who present with GI symptoms and a history of recent SARS-CoV-2 exposure or infection, even if findings seem consistent with other GI pathologies such as appendicitis, infection, or inflammatory bowel disease (IBD).

The current case demonstrates MIS- $\mathrm{C}$ as a radiologic mimic of acute appendicitis on $\mathrm{CT}$ in a patient who underwent negative appendectomy. A prior report described a case of MIS-C that mimicked appendicitis clinically and on ultrasound imaging, prompting IV antibiotics and surgery (open appendectomy and resection of an inflamed segment of ileum) before treatment with IVIG and steroids was initiated. Pathology did not show appendicitis but did show necrotic mesenteric lymphangitis and vasculitis. [13] A South African series described four children with appendicitis, confirmed by surgical findings, in the setting of SARS-CoV-2-positive PCR. MIS-C was diagnosed in three of these children after appendectomy. [14] Other case series have described appendicitis in the setting of acute SARS-CoV-2 infection. $[11,12,14]$ In addition, an increase in the rate of appendiceal perforation in children without SARSCoV-2 infections has been found during the COVID-19 pandemic, presumably due to reluctance to present to the hospital for evaluation [15]. The hyperinflammatory state seen in COVID-19 and MIS-C may play a role in the pathogenesis of intestinal involvement. There is a similar known association with Kawasaki disease and gastrointestinal manifestations, including appendicitis. $[16,17]$ Others hypothesize the contributory role of the angiotensin-converting enzyme 2 (ACE2) receptor that is expressed in the intestine, especially the terminal ileum, [18] allowing SARS-CoV-2 to invade gastrointestinal cells. [11, 12].

Our patient had some findings of appendicitis with RLQ tenderness, fever, nausea, emesis, and decreased appetite. Many of the classic signs of appendicitis (fever, anorexia, nausea, guarding, and migration of pain from the umbilical region to the RLQ) may be absent in children with appendicitis; these findings also may be present with diseases other than appendicitis. [19] Up to $20 \%$ of patients with appendicitis present without 
leukocytosis, [19] and our patient presented with an initially normal WBC count.

The patient's CT had findings concerning for acute appendicitis. CT has a sensitivity of $94 \%$ and specificity of $95 \%$ for appendicitis. [19] Causes of false positive CT include appendiceal neoplasms, IBD, cystic fibrosis, viral infections, and tubo-ovarian infection. [20] In a study of radiologic findings in MIS-C, abdominal imaging showed small-volume ascites (38\%), hepatomegaly (38\%), echogenic kidneys (31\%), bowel wall thickening (19\%), gallbladder wall thickening (19\%), mesenteric lymphadenopathy (13\%), splenomegaly (6\%), and bladder wall thickening (16\%).[21] Appendiceal dilation and fat stranding on CT, diagnostic of appendicitis and present in our patient, have not previously been described.

Non-operative management with antibiotics alone has been quite successful in managing acute uncomplicated appendicitis meeting strict inclusion criteria[22] and was a strong consideration in this patient. However, the success of antibiotics to treat appendicitis in the setting of concurrent treatment with IVIG and steroids for MIS-C is unknown with no outcomes data currently available in the literature. Additionally, given the high likelihood that the patient's abdominal symptoms would continue given her MIS-C (independent of the diagnosis of appendicitis), the team was concerned they would be unable to reliably follow her abdominal exam to determine if her appendicitis was being adequately treated with antibiotics.

While our patient's clinical presentation and radiographic findings necessitated surgical evaluation, her surgical and pathologic findings ultimately were not consistent with appendicitis. Laboratory criteria may be important in helping to differentiate MIS-C from acute appendicitis - specifically, lymphopenia, thrombocytopenia, and inappropriately normal WBC count. Our patient had a progressive lymphopenia and thrombocytopenia that did not fit with the classic presentation of appendicitis.

Patients with MIS-C can present with findings characteristic of acute appendicitis, including RLQ pain, fever, nausea, emesis, anorexia, and radiographic evidence of appendicitis. This presents a diagnostic challenge for clinicians. Although difficult to exclude appendicitis in the case of CT evidence, certain laboratory criteria, namely relative leukopenia and thrombocytopenia may be helpful in differentiating these patients. However, the use of immunomodulatory agents in the treatment of MIS-C may complicate the care of a patient with potential appendicitis, and appendectomy may still be preferable as the lowest risk option despite a low clinical suspicion for appendicitis.

\section{Abbreviations}

MIS-C: Multi-inflammatory syndrome in children; CT: Computer tomography; COVID-19: Coronavirus disease 2019; SARS-CoV-2: Severe acute respiratory syndrome coronavirus 2; RLQ: Right lower quadrant; WBC: White blood cell; IV: Intravenous; PCR: Polymerase chain reaction; IVIG: Intravenous immune globulin; GI: Gastrointestinal; IBD: Inflammatory bowel disease;

ACE2: Angiotensin-converting enzyme 2

\section{Acknowledgements}

not applicable.

\section{Author contributions}

$M H, K W, L W, E D, C K$ and SY provided direct patient care, drafted the initial manuscript, worked on literature review, and critically reviewed the manuscript. KVA and JP provided direct patient care and revised the manuscript. All authors read and approved the final manuscript as submitted and agree to be accountable for all aspects of the case report.

Funding

non-applicable (no funding source).

Availability of data and materials not applicable.

\section{Declarations}

Ethics approval and consent to participate not applicable.

\section{onsent for publication}

Written consent was obtained from the patient's parent for publication of this case report and accompanying images. A copy of the written consent is available for review by the Editor of this journal.

\section{Competing interests}

the authors have no financial or non-financial competing interests to declare.

Received: 1 April 2021 Accepted: 19 May 2021

Published online: 01 June 2021

References

1. Mehta NS, Mytton OT, Mullins EWS, et al. SARS-CoV-2 (COVID-19): What Do We Know About Children? A Systematic Review. Clin Infect Dis. 2020;71(9): 2469-79.

2. Henderson LA, Canna SW, Friedman KG, et al. American College of Rheumatology Clinical Guidance for Multisystem Inflammatory Syndrome in Children Associated With SARS-CoV-2 and Hyperinflammation in Pediatric COVID-19: Version 2. Arthritis Rheumatol. 2021;73:e13-29.

3. Dufort EM, Koumans EH, Chow EJ, et al. Multisystem Inflammatory Syndrome in Children in New York State. New Engl J Med. 2020;383(4):34758.

4. Lee PY, Day-Lewis M, Henderson LA, et al. Distinct clinical and immunological features of SARS-CoV-2-induced multisystem inflammatory syndrome in children. J Clin Invest. 2020;130(11):5942-50.

5. Carlin RF, Fischer AM, Pitkowsky Z, et al. Discriminating Multisystem Inflammatory Syndrome in Children Requiring Treatment from Common Febrile Conditions in Outpatient Settings. J Pediatr. 2021;229:26-32 e22.

6. Nakra N, Blumberg D, Herrera-Guerra A, Lakshminrusimha S. Multi-System Inflammatory Syndrome in Children (MIS-C) Following SARS-CoV-2 Infection: Review of Clinical Presentation, Hypothetical Pathogenesis, and Proposed Management. Children. 2020;7(7):69.

7. Miller J, Cantor A, Zachariah P, Ahn D, Martinez M, Margolis KG. Gastrointestinal Symptoms as a Major Presentation Component of a Novel Multisystem Inflammatory Syndrome in Children That Is Related to Coronavirus Disease 2019: A Single Center Experience of 44 Cases. Gastroenterology. 2020;159(4):1571-4 e1572.

8. Tullie L, Ford K, Bisharat M, et al. Gastrointestinal features in children with COVID-19: an observation of varied presentation in eight children. Lancet Child Adolesc Health. 2020;4(7):e19-20.

9. Jackson RJ, Chavarria HD, Hacking SM. A Case of Multisystem Inflammatory Syndrome in Children Mimicking Acute Appendicitis in a COVID-19 Pandemic Area. Cureus. 2020;12:e10722.

10. Meyer JS, Robinson G, Moonah S, et al. Acute appendicitis in four children with SARS-CoV-2 infection. J Pediatr Surg Case Rep. 2021;64:101734. 
11. Suwanwongse K, Shabarek N. Pseudo-Appendicitis in an Adolescent With COVID-19. Cureus. 2020;12:e9394.

12. Abdalhadi A, Alkhatib M, Mismar AY, Awouda W, Albarqouni L. Can COVID 19 present like appendicitis? IDCases. 2020:e00860.

13. Jackson RJ, Chavarria HD, Hacking SM. A Case of Multisystem Inflammatory Syndrome in Children Mimicking Acute Appendicitis in a COVID-19 Pandemic Area. Cureus. 2020;12(9):e10722.

14. Lishman J, Kohler C, de Vos C, et al. Acute Appendicitis in Multisystem Inflammatory Syndrome in Children With COVID-19. Pediatr Infect Dis J. 2020;39(12):e472-3.

15. Place R, Lee J, Howell J. Rate of Pediatric Appendiceal Perforation at a Children's Hospital During the COVID-19 Pandemic Compared With the Previous Year. JAMA Netw Open. 2020;3(12):e2027948.

16. Garnett GM, Kimball S, Melish ME, et al. Appendicitis as the presenting manifestation of Kawasaki disease. Pediatr Surg Int. 2014;30(5):549-52.

17. Gwendolyn M, Sarah K, Melish ME, et al. Appendicitis as the presenting manifestation of Kawasaki disease. Pediatric Surg Int. 2014;30(5):549-52.

18. Ni W, Yang X, Yang D, et al. Role of angiotensin-converting enzyme 2 (ACE2) in COVID-19. Crit Care. 2020;24(1):422.

19. Glass CC, Rangel SJ. Overview and diagnosis of acute appendicitis in children. Semin Pediatr Surg. 2016;25(4):198-203.

20. Dietz KR, Merrow AC, Podberesky DJ, Towbin AJ. Beyond acute appendicitis: imaging of additional pathologies of the pediatric appendix. Pediatr Radiol. 2013:43(2):232-42

21. Blumfield E, Levin TL, Kurian J, Lee EY, Liszewski MC. Imaging Findings in Multisystem Inflammatory Syndrome in Children (MIS-C) Associated With Coronavirus Disease (COVID-19). Am J Roentgenol. 2021;216(2):507-17.

22. Minneci $P C$, Hade EM, Lawrence AE, et al. Association of Nonoperative Management Using Antibiotic Therapy vs Laparoscopic Appendectomy With Treatment Success and Disability Days in Children With Uncomplicated Appendicitis. JAMA. 2020;324(6):581-93.

\section{Publisher's Note}

Springer Nature remains neutral with regard to jurisdictional claims in published maps and institutional affiliations.

Ready to submit your research? Choose BMC and benefit from:

- fast, convenient online submission

- thorough peer review by experienced researchers in your field

- rapid publication on acceptance

- support for research data, including large and complex data types

- gold Open Access which fosters wider collaboration and increased citations

- maximum visibility for your research: over $100 \mathrm{M}$ website views per year

At $\mathrm{BMC}$, research is always in progress.

Learn more biomedcentral.com/submissions 